Brazilian Journal

of Chemical

ISSN 0104-6632

Printed in Brazil

Engineering

www.scielo.br/bjce

Vol. 35, No. 02, pp. 659 - 668, April - June, 2018

dx.doi.org/10.1590/0104-6632.20180352s20160596

\title{
SELECTIVE CHLORINATION OF GLYCEROL TO 3-CHLORO-1,2-PROPANEDIOL CATALYZED BY BRØNSTED ACIDIC IONIC LIQUIDS
}

\author{
L. Q. Shen, Xin Zhou ${ }^{1}$, H. B. Yin ${ }^{1, *}$, X. X. Hou ${ }^{1}$ and \\ A. L. Wang ${ }^{1}$ \\ Department of Chemistry and Chemical Engineering, Faculty of Chemistry \\ and Chemical Engineering, Jiangsu University, Zhenjiang, China. Phone: \\ +86 051188787591; Fax: +86 051188791800. E-mail: 1shen@ujs.edu.cn; \\ soannstarzxzx@163.com; yin@ujs.edu.cn; 807736539@qq.com; alwang@ujs.edu.cn
}

(Submitted: October 26, 2016; Revised: January 12, 2017; Accepted: March 15, 2017)

\begin{abstract}
Brønsted acidic ionic liquids composed of 1-butyl-3-methylimidazolium, triethylbutylammonium, and 1-butylpyridinium cation counterparts and $\mathrm{HSO}_{4}^{-}$and $\mathrm{H}_{2} \mathrm{PO}_{4}^{-}$anion counterparts were used as the catalysts for the selective chlorination of glycerol with hydrogen chloride to 3-chloro-1,2-propandiol. From the perspective of the glycerol conversion and product yields, the catalytic activities of the ionic liquids containing $\mathrm{HSO}_{4}^{-}$were higher than the ionic liquids containing $\mathrm{H}_{2} \mathrm{PO}_{4}^{-}$. As compared with the carboxylic acid catalysts, Brønsted acidic ionic liquids favored the catalytic chlorination of glycerol to 3-chloro-1,2-propandiol. When the glycerol chlorination was catalyzed by the Brønsted acidic ionic liquids at $110^{\circ} \mathrm{C}$ for $12 \mathrm{~h}$ with the catalyst loading of 0.75 $\mathrm{mol} \cdot \mathrm{kg}^{-1}$ glycerol, the 3-chloro-1,2-propandiol yield was more than $81 \%$ at the complete conversion of glycerol.
\end{abstract}

Keywords: Glycerol, 3-Chloro-1,2-dipropanol, Brønsted acidic ionic liquids, Chlorination.

\section{INTRODUCTION}

Biodiesel is an environmentally friendly and renewable fuel. With the rapid growth of biodiesel production, glycerol is produced as the main byproduct, ca. $10 \%$ of biodiesel, causing the glycerol market to be oversupplied (Katryniok et al., 2013; Tesser et al., 2007; Yi et al., 2014). Nowadays, researchers have paid great attention to the conversion of glycerol to high-valued chemicals, such as propanediol, propylene glycol, dichloropropanol, acrolein, and acrylic acid by hydrogenolysis (Dasari et al., 2005; Ma et al., 2008), catalytic chlorination (Santacesaria et al., 2010), dehydration (Shen et al., 2012), and oxydehydration methods (Shen et al., 2014; Zhou et al., 2007). Monochloropropandiol is produced as an intermediate chemical for dichloropropanol production.

3-Chloro-1,2-propandiol (3-MCPD) is an important raw material for the production of glycerol carbonate and glycidol (Choi et al., 2013; Gade et al., 2012; Gómez-Jiménez-Aberasturi et al., 2010; OchoaGómez et al., 2011; Pagliaro and Rossi 2010), which are used for the synthesis of polymers, pharmaceuticals, cosmetics, and photochemicals. Furthermore, chiral 3-MCPD is an important medical intermediate for the synthesis of $L$-carnitine (Li et al., 2011; Yang et al., 2011). 3-MCPD is conventionally produced by the hydrolysis of epoxy chloropropane, which 
is produced by using propylene as a starting material via chlorination, chlorohydrination, and subsequent saponification processes (Carrà et al., 1979; Nadato et al., 1987). However, the production process is very complicated. In the production of dichloropropanol via the chlorination of glycerol, 3-MCPD is produced first as an intermediate product, which can be rapidly chlorinated to dichloropropanol over carboxylic acid catalysts (de Araujo Filho et al., 2016; de Araujo Filho et al., 2016; Hou et al., 2015). Over heteropolyacid catalysts, 3-MCPD with a maximum selectivity of $42.3 \%$ was obtained, accompanied by the formation of dichloropropanol and other byproducts (Song et al., 2010). Selective chlorination of glycerol to 3-MCPD with a high selectivity is worthy of investigation.

Recently, reactions catalyzed by ionic liquids have attracted the interest of researchers in virtue of their negligible vapor pressure, high thermal stability, high ionic conductivity, and composition tunability (Chen et al., 2010;Duan et al., 2006; Olivier-Bourbigou and Magna, 2002; Wang et al., 2012). Brønsted acidic ionic liquids bearing acid anions and organic cations, such as $\mathrm{HSO}_{4}^{-}, \mathrm{H}_{2} \mathrm{PO}_{4}^{-},[\mathrm{Bmim}]^{+},[\mathrm{BPy}]^{+}$, and $\left[\mathrm{N}_{2224}\right]^{+}$, have been used in many typical acid-catalyzed organic reactions (Srivastava, 2010; Wang et al., 2008; Wang et al., 2008). The acidity of Brønsted acidic ionic liquids can be changed by changing the components of the anion counterparts, which affect their catalytic activities for acid-catalyzed reactions. Brønsted acidic ionic liquids not only supply protons for catalyzing the chlorination of glycerol, their steric effect may also affect the selectivity of chlorinated product.

In the present work, the catalytic performances of the Brønsted acidic ionic liquids composed of 1-butyl-3-methylimidazolium $\left([\mathrm{Bmim}]^{+}\right)$, triethylbutylammonium $\left(\left[\mathrm{N}_{2224}\right]^{+}\right)$, and 1-butylpyridinium $\left([\mathrm{BPy}]^{+}\right)$cation counterparts and $\mathrm{HSO}_{4}^{-}$and $\mathrm{H}_{2} \mathrm{PO}_{4}^{-}$anion counterparts were investigated for the chlorination reaction of glycerol with HCl. The acidities of the Brønsted acidic ionic liquids were evaluated by UV-vis spectroscopy. Brønsted acid sites of the Brønsted acidic ionic liquids were determined by a FT-IR technique with the use of pyridine as a probe molecule. The effect of reaction parameters, reaction temperature and catalyst loading, on the chlorination reaction was investigated. The reaction routes were also briefly discussed.

\section{MATERIALS AND METHODS}

\section{Chemicals}

Hydrogen chloride was of industrial grade and was purchased from Shandong Wangdali Co. Ltd.
2-Chloro-1,3-propandiol (2-MCPD), 3-MCPD, 1,3-dichloro-1-propanol (1,3-DCP), and 2,3-dichloro1-propanol (2,3-DCP) were purchased from Xiya Chemical Reagents Co. Ltd. 1-Methylimidazole, triethylamine, pyridine, $n$-butyl bromide, phosphoric acid, sulfuric acid, glycerol, and $n$-butanol were of reagent grade and were purchased from Sinopharm Chemical Reagent Co. Ltd. All chemicals were used as received without further purification.

\section{Synthesis of Bronsted acidic ionic liquids}

Synthesis of 1-butyl-3-methylimidazolium bromide ([Bmim]Br). According to the reported method (Ramenskaya et al., 2008), [Bmim]Br was synthesized as follows. $N$-Methylimidazole $(0.5 \mathrm{~mol})$ and $n$-butyl bromide $(0.55 \mathrm{~mol})$ were added into a $250 \mathrm{~mL}$ threenecked flask equipped with a reflux condenser under stirring and a nitrogen atmosphere. The reaction was carried out under reflux for $10 \mathrm{~h}$. The resultant mixture was cooled to room temperature and the assynthesized [Bmim] Br was washed with ethyl acetate thrice. The remaining ethyl acetate was removed with a rotary evaporator at $70^{\circ} \mathrm{C}$ and $[\mathrm{Bmim}] \mathrm{Br}$ was dried in a vacuum oven at $70{ }^{\circ} \mathrm{C}$ for $24 \mathrm{~h}$.

Synthesis of 1-butyl-3-methylimidazolium hydrogen sulfate ([Bmim] $\left.\mathrm{HSO}_{4}\right)$ and 1-butyl-3methylimidazolium dihydrogen phosphate ([Bmim] $\mathrm{H}_{2} \mathrm{PO}_{4}$ ) (Dubreuil et al., 2002; Wang et al., 2008). Given amount of [Bmim] Br was added in a threenecked flask in an ice-water bath and then concentrated sulfuric acid $(98 \%)$ or phosphoric acid $(85 \%)$ in the same mole amount as that of $[\mathrm{Bmim}] \mathrm{Br}$ was added dropwise into it under vigorous stirring. The mixture was slowly heated up to $60{ }^{\circ} \mathrm{C}$ and stirred for $18 \mathrm{~h}$. The as-synthesized $[\mathrm{Bmim}] \mathrm{HSO}_{4}$ and $[\mathrm{Bmim}] \mathrm{H}_{2} \mathrm{PO}_{4}$ samples were evaporated with a rotary evaporator and dried in a vacuum at $70{ }^{\circ} \mathrm{C}$ for $24 \mathrm{~h}$.

Synthesis of 1-butylpyridinium bromide ([BPy]Br) (Xiong and Yang, 2014). Under nitrogen atmosphere, $20 \mathrm{~mL}$ of ethanol as solvent and $0.5 \mathrm{~mol}$ of pyridine were added to a $250 \mathrm{~mL}$ three-necked flask with a reflux condenser. Then $0.55 \mathrm{~mol}$ of $n$-butyl bromide was added under reflux and stirring for $4 \mathrm{~h}$. The solvent and unreacted chemicals were separated from the reaction solution by reduced pressure distillation technique. The as-prepared [BPy] $\mathrm{Br}$ was cooled to room temperature, washed with ethyl acetate $(3 \times 20$ $\mathrm{mL}$ ), and recrystallized in dichloromethane. The [BPy] Br sample was dried in a vacuum oven at $50{ }^{\circ} \mathrm{C}$ for $24 \mathrm{~h}$.

Synthesis of 1-butylpyridinium hydrogen sulfate $\left([\mathrm{BPy}] \mathrm{HSO}_{4}\right)$ and 1-butylpyridinium dihydrogen 
phosphate $\left([\mathrm{BPy}] \mathrm{H}_{2} \mathrm{PO}_{4}\right)$ (Du et al., 2006). The synthesis procedures for $[\mathrm{BPy}] \mathrm{HSO}_{4}$ and $[\mathrm{BPy}] \mathrm{H}_{2} \mathrm{PO}_{4}$ were the same as those mentioned for the synthesis of $[\mathrm{Bmim}] \mathrm{HSO}_{4}$ and $[\mathrm{Bmim}] \mathrm{H}_{2} \mathrm{PO}_{4}$.

Synthesis of triethylbutylammonium bromide $\left(\left[\mathrm{N}_{2224}\right] \mathrm{Br}\right)$ (Yu et al., 2009). Under a nitrogen atmosphere, $0.5 \mathrm{~mol}$ of triethylamine and $0.5 \mathrm{~mol}$ of $n$-butyl bromide were added into a $250 \mathrm{~mL}$ threenecked flask containing $50 \mathrm{~mL}$ ethanol and reacted under reflux for $24 \mathrm{~h}$. The resultant mixture was washed with ethyl acetate thrice. The remaining ethyl acetate was removed with a rotary evaporator and white solid $\left[\mathrm{N}_{2224}\right] \mathrm{Br}$ was dried in a vacuum oven at $60^{\circ} \mathrm{C}$ for $24 \mathrm{~h}$.

Synthesis of triethylbutylammonium hydrogen sulfate $\left(\left[\mathrm{N}_{2224}\right] \mathrm{HSO}_{4}\right)$ and triethylbutylammonium dihydrogen phosphate $\left(\left[\mathrm{N}_{2224}\right] \mathrm{H}_{2} \mathrm{PO}_{4}\right)$ ( ${ }^{\text {Attri }}$ et al. $\left.{ }^{2011}\right)$. The synthesis procedures for $\left[\mathrm{N}_{2224}\right] \mathrm{HSO}_{4}$ and $\left[\mathrm{N}_{2224}\right]$ $\mathrm{H}_{2} \mathrm{PO}_{4}$ were the same as those mentioned for the synthesis of $[\mathrm{Bmim}] \mathrm{HSO}_{4}$ and $[\mathrm{Bmim}] \mathrm{H}_{2} \mathrm{PO}_{4}$.

\section{Characterization of Bronsted acidic ionic liquids}

\section{Determination of acid sites of Brønsted acidic ionic liquids}

Brønsted acid sites of the ionic liquids were determined using pyridine as a probe molecule by monitoring the band range of $1300-1600 \mathrm{~cm}^{-1}$ (Qureshi et al., 2009; Yang and Kou, 2004). All samples were prepared by mixing pyridine and ionic liquid with a mole ratio of $3: 1$. The spectra were recorded on a FTIR spectrophotometer (Nicolet Nexus 470) at room temperature.

\section{UV-vis acidity evaluation}

The Hammett function is used to evaluate the Brønsted acidity of a Brønsted acidic ionic liquid in a solution with a basic indicator to trap the dissociative proton. The Hammett acidity function was detected using UV-vis spectroscopy (Gu et al., 2005; Thomazeau et al., 2003). This method consists of evaluating the protonation extent of the uncharged indicator base (named I) in a solution, in terms of the measurable ratio $[\mathrm{I}] /\left[\mathrm{IH}^{+}\right]$. The Hammett function $\left(H_{0}\right)$ is defined as follows:

$$
H_{0}=p k(I)_{a q}+\log \left([I] /\left[I H^{+}\right]\right)
$$

To evaluate the acidities of those above-mentioned Brønsted acidic ionic liquids, 4-nitroaniline was chosen as the indicator (the concentration was $10 \mathrm{mmol} / \mathrm{L}$, the Hammett content is 0.99 in dichloromethane). After adding a molar equivalent of Brønsted acidic ionic liquids into the dichloromethane solution of 4-nitroanline, the UV-vis absorbance of the unprotonated 4-nitroanline was recorded with an Analytik Jena S600 spectrophotometer at $350 \mathrm{~nm}$.

\section{Chlorination reaction}

Fifty grams of glycerol and a given amount of Brønsted acidic ionic liquids with the ratios of ionic liquid to glycerol of $0.25-1.0 \mathrm{~mol} \mathrm{~kg}^{-1}$ were added into a $100 \mathrm{~mL}$ four-necked round bottom flask equipped with a hydrogen chloride inlet tube, a thermometer, a condenser, and a magnetic stirrer under stirring at $100 \mathrm{rpm}$. Nitrogen stream was introduced into the reactor to replace the air inside the reactor before the chlorination reaction. When the reaction solution was heated to a prescribed temperature $\left(70-130^{\circ} \mathrm{C}\right)$, hydrogen chloride was introduced into the reactor

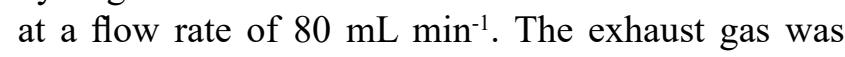
absorbed with an aqueous alkali solution.

The reaction mixture was analyzed on a gas chromatograph, equipped with a flame ionization detector (FID) and a PEG capillary column $(0.25 \mathrm{~mm}$ $\times 30 \mathrm{~m})$. $n$-Butanol was used as an internal standard sample. The conversion of glycerol and the yields of 2-MCPD, 3-MCPD, 1,3-DCP, and 2,3-DCP were calculated according to the following equations.

$$
\begin{gathered}
\text { Glycerol Conversion }=\frac{\text { Glycerol }_{\text {in }}-\text { Glycerol }_{\text {out }}}{\text { Glycerol }_{\text {in }}} \times 100 \% \\
\text { Product Yield }=\frac{\text { Product }_{\text {out }}}{\text { Glycerol }_{\text {in }}} \times 100 \%
\end{gathered}
$$

\section{RESULTS AND DISCUSSION}

\section{Acid sites of Brønsted acidic ionic liquids}

Although the pyridine adsorption method can not be used to quantitatively detect the amount of Brønsted acid in ionic liquids, it is widely used to determine the presence of Brønsted acid sites (Bui et al. 2012; Yang and Kou, 2004). The presence of a peak near $1540 \mathrm{~cm}^{-}$ ${ }^{1}$ is an indication of the formation of pyridinium ions resulting from the presence of Brønsted acid sites.

As shown in Fig. 1, pure pyridine shows a well resolved band at $1438 \mathrm{~cm}^{-1}$. When pyridine was mixed with nine Brønsted acidic ionic liquids, the adsorption peaks appearing at $1540 \mathrm{~cm}^{-1}$ were observed, indicating the presence of Brønsted acid sites in all the samples. 


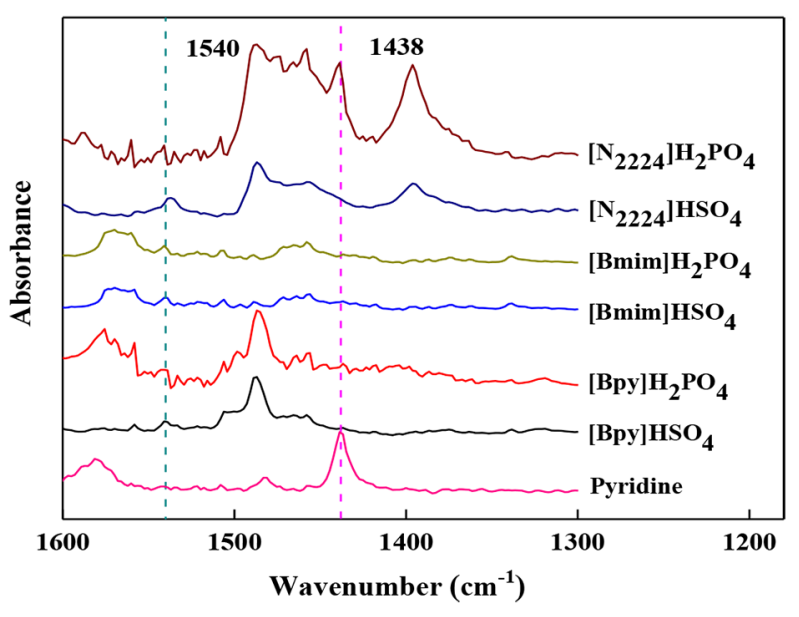

Figure 1. FT-IR spectra of pyridine with Brønsted acidic ionic liquids. The mole ratio of pyridine to ionic liquid is $3: 1$.

\section{Acidities of Brønsted acidic ionic liquids}

The absorption spectra of 4-nitroaniline for various Brønsted acidic ionic liquids in dichloromethane are shown in Fig. 2. The values of [I], [I]/[IH $\left.{ }^{+}\right]$, and $H_{0}$ are listed in Table 1. The $H_{0}$ values were in the order $\left[\mathrm{N}_{2224}\right]$ $\mathrm{H}_{2} \mathrm{PO}_{4}>[\mathrm{Bmim}] \mathrm{H}_{2} \mathrm{PO}_{4}>[\mathrm{BPy}] \mathrm{H}_{2} \mathrm{PO}_{4}>\left[\mathrm{N}_{2224}\right] \mathrm{HSO}_{4}$ $>[\mathrm{Bmim}] \mathrm{HSO}_{4}>[\mathrm{BPy}] \mathrm{HSO}_{4}$. The results revealed that the Brønsted acidic ionic liquids containing $\mathrm{HSO}_{4}^{-}$ anion possessed higher acidity than those containing $\mathrm{H}_{2} \mathrm{PO}_{4}^{-}$anion. Furthermore, the acidity of the Brønsted acidic ionic liquid was also influenced by the cation type. The effect of the cations on the acidity was in the order of $[\mathrm{BPy}]^{+}>[\mathrm{Bmim}]^{+}>\left[\mathrm{N}_{2224}\right]^{+}$.

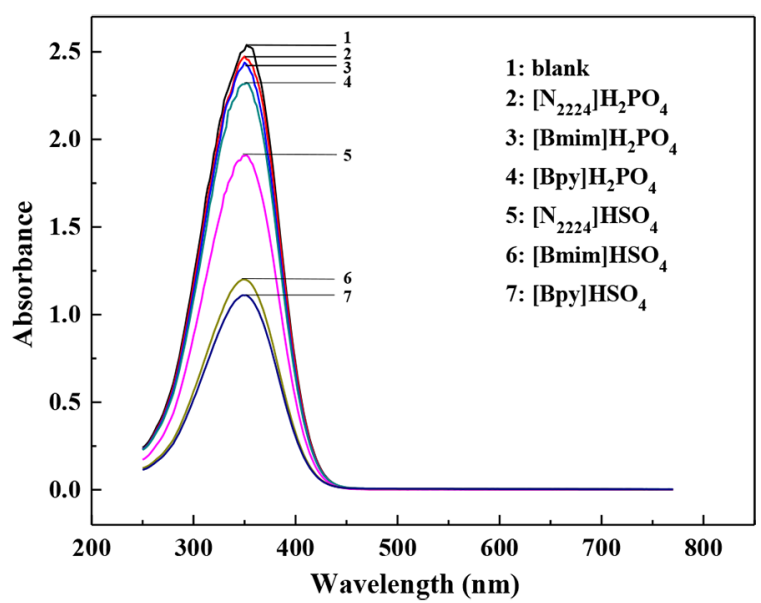

Figure 2. Absorption spectra of 4-nitroaniline for various Brønsted acidic ionic liquids in dichloromethane.

\section{Chlorination reaction catalyzed by Brønsted acidic ionic liquids}

\section{Conversion of glycerol}

Fig. 3 shows the conversions of glycerol in the glycerol chlorination reaction with gaseous $\mathrm{HCl}$ catalyzed by the Brønsted acidic ionic liquids with the catalyst loading of $0.75 \mathrm{~mol} \mathrm{~kg}^{-1}$ glycerol at $110^{\circ} \mathrm{C}$.

When the chlorination reaction was carried out without catalyst, prolonging the reaction time from $3 \mathrm{~h}$ to $12 \mathrm{~h}$, the conversions of glycerol gradually increased from $27.6 \%$ to $68.72 \%$. When [Bmim] $\mathrm{H}_{2} \mathrm{PO}_{4}$ and $[\mathrm{Bmim}] \mathrm{HSO}_{4}$ were used as the catalysts for glycerol chlorination at $110^{\circ} \mathrm{C}$ for $3 \mathrm{~h}$, the conversions of glycerol were $58.73 \%$ and $66.29 \%$, respectively. After reacting for $12 \mathrm{~h}$, the conversions reached $100 \%$. When $[\mathrm{BPy}] \mathrm{H}_{2} \mathrm{PO}_{4}$ and $[\mathrm{BPy}] \mathrm{HSO}_{4}$ were used as the catalysts at $110{ }^{\circ} \mathrm{C}$ for $3 \mathrm{~h}$, the conversions of glycerol were $56.57 \%$ and $65.04 \%$, respectively. After reacting for $12 \mathrm{~h}$, the conversions reached $99.1 \%$ and $100 \%$. When $\left[\mathrm{N}_{2224}\right] \mathrm{H}_{2} \mathrm{PO}_{4}$ and $\left[\mathrm{N}_{2224}\right] \mathrm{HSO}_{4}$ were used as the catalysts at $110{ }^{\circ} \mathrm{C}$ for $3 \mathrm{~h}$, the conversions of glycerol were $50.25 \%$ and $63.92 \%$, respectively. Prolonging the reaction time to $12 \mathrm{~h}$, the conversions reached $94.4 \%$ and $99.2 \%$.

The results revealed that the Brønsted acidic ionic liquids exhibited good catalytic activity for the chlorination of glycerol. The chlorination rates for all the ionic liquids in first $3 \mathrm{~h}$ were in the order [Bmim] $\mathrm{HSO}_{4}(66.29 \%)>[\mathrm{BPy}] \mathrm{HSO}_{4}(65.04 \%)>\left[\mathrm{N}_{2224}\right] \mathrm{HSO}_{4}$ $(63.92 \%)>[\mathrm{Bmim}] \mathrm{H}_{2} \mathrm{PO}_{4}(58.73 \%)>\left[\mathrm{BPy}^{2} \mathrm{H}_{2} \mathrm{PO}_{4}\right.$ $(56.57 \%)>\left[\mathrm{N}_{2224}\right] \mathrm{H}_{2} \mathrm{PO}_{4}(50.25 \%)>>$ without the use of catalyst $(27.59 \%)$.

Without the use of catalyst, glycerol was chlorinated with $\mathrm{HCl}$. It can be explained as the results of the acidic protons $\left(\mathrm{H}^{+}\right)$formed by the hydrolysis of $\mathrm{HCl}$ catalyzing glycerol chlorination. However, $\mathrm{HCl}$ is more volatile and is the reason why a lower glycerol conversion was obtained. Although the Brønsted acidic ionic liquids with the same loading of $0.75 \mathrm{~mol}$ $\mathrm{kg}^{-1}$ were used for the chlorination of glycerol and the Brønsted acidic ionic liquids with $\mathrm{H}_{2} \mathrm{PO}_{4}^{-}$anions could supply more protons than those with $\mathrm{HSO}_{4}$ anions for the chlorination reaction, the latter gave higher catalytic activities than the former. The results revealed that the Brønsted acidic ionic liquid with high 
Table 1. $\mathrm{H}_{0}$ values of various Brønsted acidic ionic liquids in dichloromethane. ${ }^{\mathrm{a}}$

\begin{tabular}{lcccc}
\hline BAILs & Absorbance $[\mathrm{AU}]$ & {$[\mathrm{I}][\%]$} & {$\left[\mathrm{HI}^{+}\right][\%]$} & - \\
\hline Blank & 2.5386 & 100 & 0 & $\boldsymbol{H}_{0}$ \\
{$\left[\mathrm{~N}_{2224}\right] \mathrm{H}_{2} \mathrm{PO}_{4}$} & 2.4737 & 97.4 & 2.6 & 2.56 \\
{$[\mathrm{Bmim}] \mathrm{H}_{2} \mathrm{PO}_{4}$} & 2.4382 & 96.0 & 4.0 & 2.37 \\
{$[\mathrm{BPy}] \mathrm{H}_{2} \mathrm{PO}_{4}$} & 2.3220 & 91.5 & 8.5 & 2.02 \\
{$\left[\mathrm{~N}_{2224}\right] \mathrm{HSO}_{4}$} & 1.9103 & 75.3 & 24.7 & 1.47 \\
{$[\mathrm{Bmim}] \mathrm{HSO}_{4}$} & 1.2003 & 47.3 & 52.7 & 0.94 \\
{$[\mathrm{BPy}] \mathrm{HSO}_{4}$} & 1.1103 & 43.7 & 56.3 & 0.88 \\
\hline
\end{tabular}

${ }^{\mathrm{a} C o n c e n t r a t i o n: ~} 10 \mathrm{mmol} / \mathrm{L}$; indicator: 4-nitroanline.

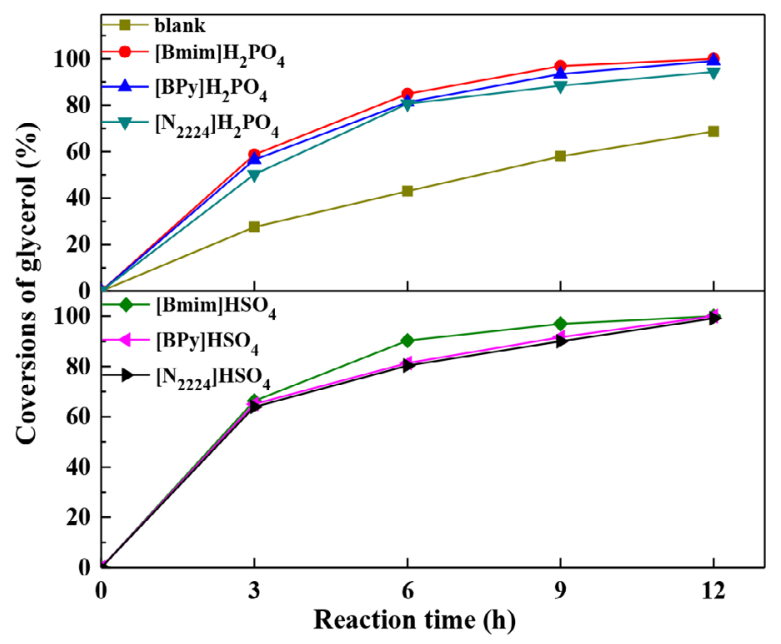

Figure 3. The conversions of glycerol in chlorination reactions with gaseous $\mathrm{HCl}$ catalyzed by Brønsted acidic ionic liquids with the catalyst loading of $0.75 \mathrm{~mol} \mathrm{~kg}^{-1}$ glycerol at $110^{\circ} \mathrm{C}$.

Brønsted acidity exhibited high catalytic activity for the chlorination of glycerol. Furthermore, the types of organic cations in the Brønsted acidic ionic liquids probably also affected their catalytic activities. YIELD OF PRODUCT

The product yields in the chlorination of glycerol catalyzed by the as-prepared Brønsted acidic ionic liquids are shown in Fig. 4.

When the chlorination reaction was carried out without the use of catalyst, after reacting for $12 \mathrm{~h}$, the yields of 3-MCPD, 2-MCPD, 1,3-DCP, and 2,3-DCP were $59.83 \%, 3.75 \%, 4.78 \%$, and $0.35 \%$, respectively.

When the chlorination of glycerol was catalyzed by the $[\mathrm{Bmim}] \mathrm{H}_{2} \mathrm{PO}_{4}$ and $[\mathrm{Bmim}] \mathrm{HSO}_{4}$ Brønsted acidic ionic liquids at $110{ }^{\circ} \mathrm{C}$, prolonging the reaction time from 3 to $12 \mathrm{~h}$, the yields of 3-MCPD increased from $53.15 \%$ to $81.86 \%$ and from $58.50 \%$ to $81.62 \%$, respectively. The yields of 1,3-DCP increased from $3.08 \%$ to $13.16 \%$ and from $3.88 \%$ to $13.58 \%$. The maximum yields of $2-\mathrm{MCPD}$ of $4.70 \%$ and $4.46 \%$ were obtained after reacting for $9 \mathrm{~h}$ and $12 \mathrm{~h}$, respectively. After $12 \mathrm{~h}$, the yields of 2,3-DCP were less than $0.32 \%$ and $0.34 \%$, respectively.
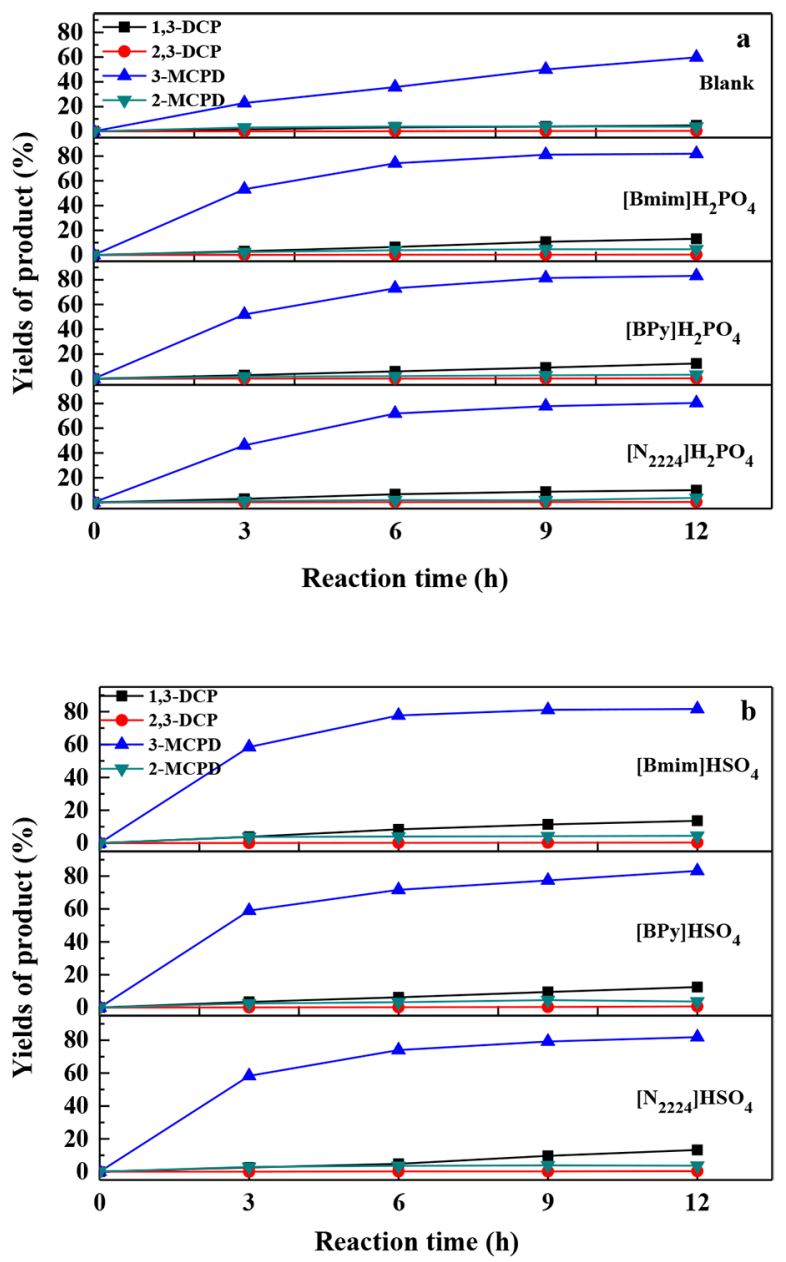

Figure 4. Yields of products in the chlorination of glycerol catalyzed by Brønsted acidic ionic liquids with the catalyst loading of $0.75 \mathrm{~mol} / \mathrm{kg}$ glycerol at $110^{\circ} \mathrm{C}$.

When the chlorination of glycerol was catalyzed by the $[\mathrm{BPy}] \mathrm{H}_{2} \mathrm{PO}_{4}$ and $[\mathrm{BPy}] \mathrm{HSO}_{4}$ Brønsted acidic ionic liquids at $110^{\circ} \mathrm{C}$, prolonging the reaction time from 3 to $12 \mathrm{~h}$, the yields of 3-MCPD increased from $51.93 \%$ to $83.21 \%$ and from $58.97 \%$ to $83.12 \%$, respectively. The yields of 1,3-DCP increased from $2.82 \%$ to $12.34 \%$ and from $3.46 \%$ to $12.46 \%$. The maximum yields of 2-MCPD of $3.16 \%$ and $4.54 \%$ were obtained after 
reacting for 12 and $9 \mathrm{~h}$, respectively. After $12 \mathrm{~h}$, the yields of 2,3-DCP were less than $0.34 \%$ and $0.70 \%$.

When the chlorination of glycerol was catalyzed by $\left[\mathrm{N}_{2224}\right] \mathrm{H}_{2} \mathrm{PO}_{4}$ and $\left[\mathrm{N}_{2224}\right] \mathrm{HSO}_{4}$ Brønsted acidic ionic liquids at $110^{\circ} \mathrm{C}$, with the increase of reaction time from $3 \mathrm{~h}$ to $12 \mathrm{~h}$, the yields of 3-MCPD increased from $46.15 \%$ to $80.43 \%$ and from $58.29 \%$ to $81.82 \%$. The yields of 1,3-DCP increased from $2.83 \%$ to $9.9 \%$ and from $2.60 \%$ to $13.27 \%$. The maximum yields of 2-MCPD of $3.63 \%$ and $3.89 \%$ were obtained after reacting for 12 and $9 \mathrm{~h}$, respectively. After $12 \mathrm{~h}$, the yields of 2,3-DCP were less than $0.38 \%$ and $0.34 \%$.

Over the Brønsted acidic ionic liquid catalysts, the 3-MCPD yield stayed at a high level of $c a$. $80 \%$ for a long reaction time. The 1,3-DCP yield was less than 14\% and a small amount of 2-MCPD and 2,3DCP were formed. Furthermore, as compared with the case using carboxylic acid as the catalyst (Hou et al., 2015), the 3-MCPD yield increased by $10 \%$ over the Brønsted acidic ionic liquid catalysts, indicating that the Brønsted acidic ionic liquids favored the chlorination of glycerol to 3-MCPD, probably due to the steric hindrance effect of large molecules.

\section{Effect of reaction temperature}

Considering that the $[\mathrm{Bmim}] \mathrm{HSO}_{4}$ catalyst exhibited a higher reaction rate than the other Brønsted acidic ionic liquid catalysts, it was taken as the model catalyst to investigate the effect of other experimental parameters on the glycerol chlorination reaction.

Fig. 5 shows the conversion of glycerol and yields of products in the chlorination of glycerol with $\mathrm{HCl}$ catalyzed by the $[\mathrm{Bmim}] \mathrm{HSO}_{4}$ ionic liquid with the catalyst loading of $0.75 \mathrm{~mol} \cdot \mathrm{kg}^{-1}$ glycerol at different reaction temperatures.

When the reaction temperatures were 70 and 90 ${ }^{\circ} \mathrm{C}$, the conversions of glycerol were $22.57 \%$ and $56.23 \%$ after reacting for $12 \mathrm{~h}$ (Fig. 5a). Glycerol was completely converted after reacting at 100 and $130{ }^{\circ} \mathrm{C}$ for 12 and $6 \mathrm{~h}$, respectively. High reaction temperature favored glycerol conversion.

After reacting for $12 \mathrm{~h}$, increasing the reaction temperatures from 70 to $110{ }^{\circ} \mathrm{C}$, the yields of 3-MCPD increased from $21.43 \%$ to $81.62 \% \%$, the yields of $2-\mathrm{MCPD}$ increased from $0.80 \%$ to $4.46 \%$, the yields of 1,3 -DCP increased from $0.31 \%$ to $13.58 \%$, and the yields of 2,3-DCP increased from $0.04 \%$ to $0.34 \%$. However, when the reaction temperature was increased to $130{ }^{\circ} \mathrm{C}$, the maximum yield of 3-MCPD of $85.39 \%$ was obtained after reacting for $6 \mathrm{~h}$, indicating that the high reaction temperature favored the chlorination of glycerol to 3-MCPD in a short reaction time period.
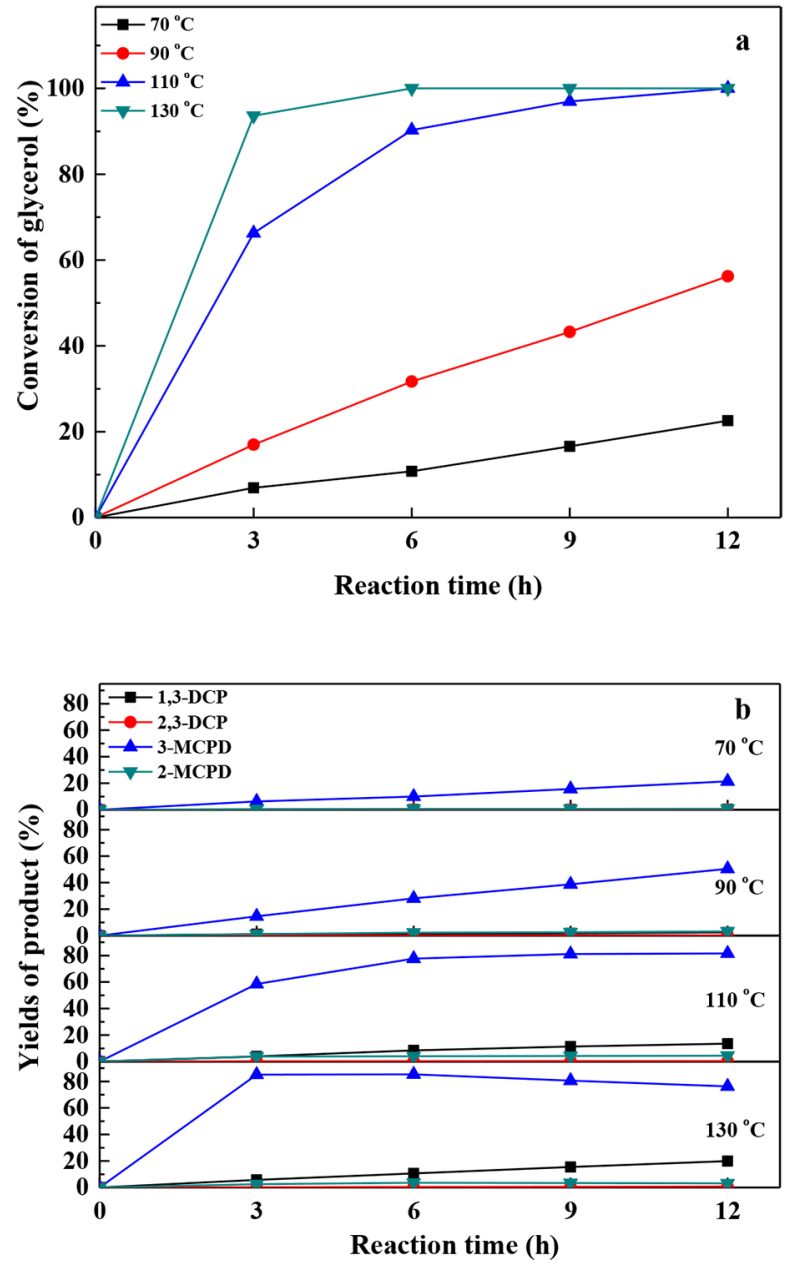

Figure 5. The conversions of glycerol and yields of products in the chlorination of glycerol with $\mathrm{HCl}$ catalyzed by $[\mathrm{Bmim}] \mathrm{HSO}_{4}$ ionic liquid with the catalyst loading of $0.75 \mathrm{~mol} / \mathrm{kg}$ glycerol at different reaction temperatures.

\section{Effect of catalyst loading}

Fig. 6 shows the conversions of glycerol and yields of products in the chlorination of glycerol with $\mathrm{HCl}$ catalyzed by the $[\mathrm{Bmim}] \mathrm{HSO}_{4}$ ionic liquid with different catalyst loadings at $110^{\circ} \mathrm{C}$.

The conversions of glycerol slightly increased with increasing catalyst loading. When the catalyst loading was increased to $0.5 \mathrm{~mol} / \mathrm{kg}$ glycerol, after reacting for $12 \mathrm{~h}$, glycerol was completely converted (Fig. 6a).

After reacting at $110{ }^{\circ} \mathrm{C}$ for $12 \mathrm{~h}$, increasing the catalyst loadings from 0.25 to $1.0 \mathrm{~mol} / \mathrm{kg}$ glycerol, the yields of 1,3-DCP slightly increased from $8.43 \%$ to $18.33 \%$, the yields of 2-MCPD and 2,3-DCP were less than $4.50 \%$ and $0.44 \%$, respectively (Fig. $6 \mathrm{~b}$ ). The maximum 3-MCPD yield of $81.62 \%$ was obtained at the catalyst loading of $0.75 \mathrm{~mol} \cdot \mathrm{kg}^{-1}$ glycerol, indicating that 3-MCPD could be chlorinated to DCP at a high catalyst loading level. 

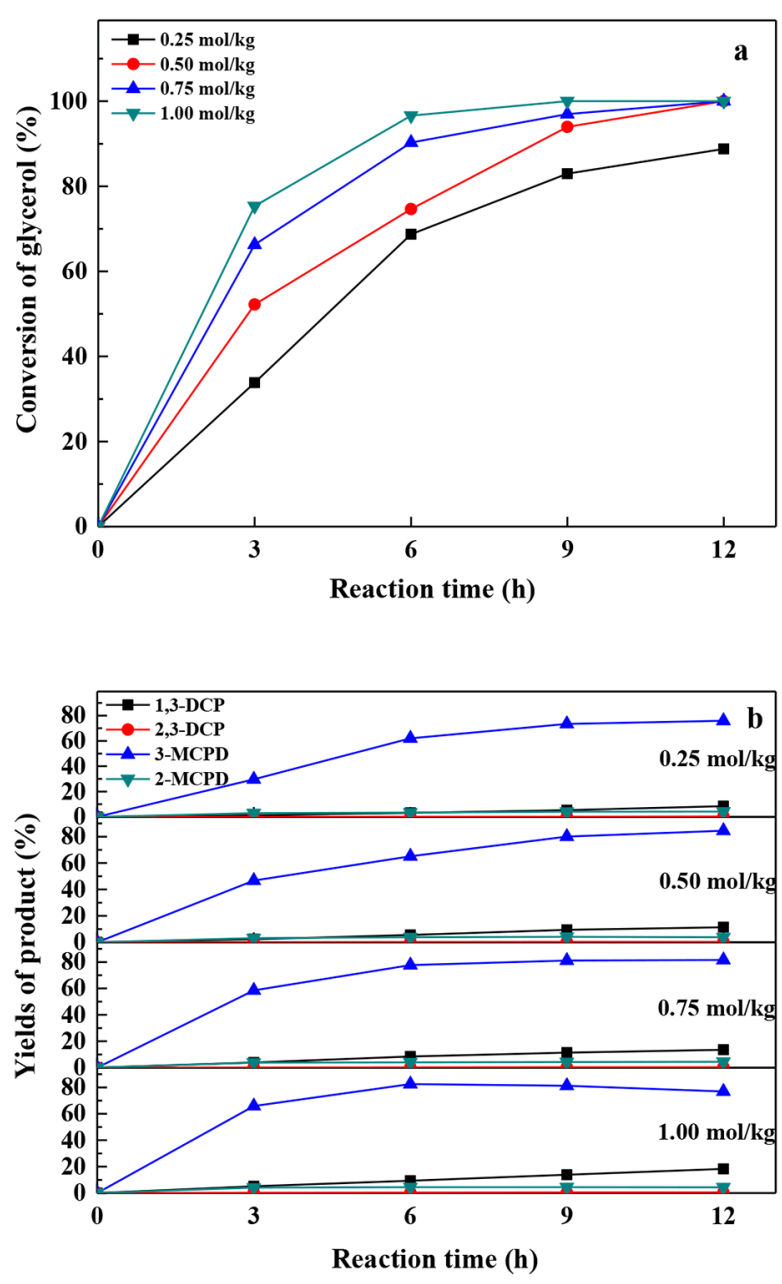

Figure 6. The conversion of glycerol and yields of products in the chlorination of glycerol with $\mathrm{HCl}$ catalyzed by $[\mathrm{Bmim}] \mathrm{HSO}_{4}$ ionic liquid with different catalyst loadings at $110^{\circ} \mathrm{C}$.

\section{Reaction routes}

When the Brønsted acidic ionic liquids were used as the catalysts in the chlorination of glycerol, 3-MCPD was produced as the main product. Small amounts of 2-MCPD, 1,3-DCP, and 2,3-DCP were detected. The reaction mechanism in the glycerol chlorination catalyzed by Brønsted acidic ionic liquid was suggested as that in Scheme 1.
For the chlorination of glycerol to 3-MCPD catalyzed by Brønsted acidic ionic liquids, it is suggested that the glycerol molecule is first protonated at the terminal hydroxyl group by a proton from the Brønsted acidic ionic liquid and then the resultant protonated glycerol is attacked by a chloride anion to form 3-MCPD, accompanied by the formation of $\mathrm{H}_{2} \mathrm{O}$. The resultant 3-MCPD could be protonated at the terminal hydroxyl group by ionic liquid catalyst and then chlorinated by chloride anion to form 1,3-DCP.

2-MCPD can be produced via the protonation at the middle hydroxyl group of glycerol. The steric hindrance effect of the large ionic liquid molecule favored the formation of 3-MCPD rather than 2-MCPD. With the reaction going on, 2-MCPD can be further chlorinated to form 2,3-DCP. The spent Brønsted acid sites can be re-protonated by the protons abundant in the solution.

The experimental results showed that the yields of products changed upon prolonging the reaction time, indicating that all the chlorination reactions were under kinetic control rather than thermodynamic control. Furthermore, the formation rate of 3-MCPD was much higher than those of other products, revealing that the Brønsted acidic ionic liquids favored the chlorination of glycerol to 3-MCPD.

\section{CONCLUSIONS}

Catalytic chlorination of glycerol with $\mathrm{HCl}$ to 3-MCPD over Brønsted acidic ionic liquid catalysts with 1-butyl-3-methylimidazolium, triethylbutylammonium, and 1-butylpyridinium as the cation counterparts and $\mathrm{HSO}_{4}^{-}$and $\mathrm{H}_{2} \mathrm{PO}_{4}^{-}$as the anion counterparts was investigated. The acidities of the Brønsted acidic ionic liquids were in the order of ionic liquids containing $\mathrm{HSO}_{4}^{-}$anion $>$ionic liquids containing $\mathrm{H}_{2} \mathrm{PO}_{4}^{-}$ anion. The ionic liquids with high acidity gave high catalytic activity for glycerol chlorination. The Brønsted acidic ionic liquids exhibited high catalytic activities for the selective chlorination of glycerol to 3-MCPD. When the chlorination of glycerol was catalyzed by

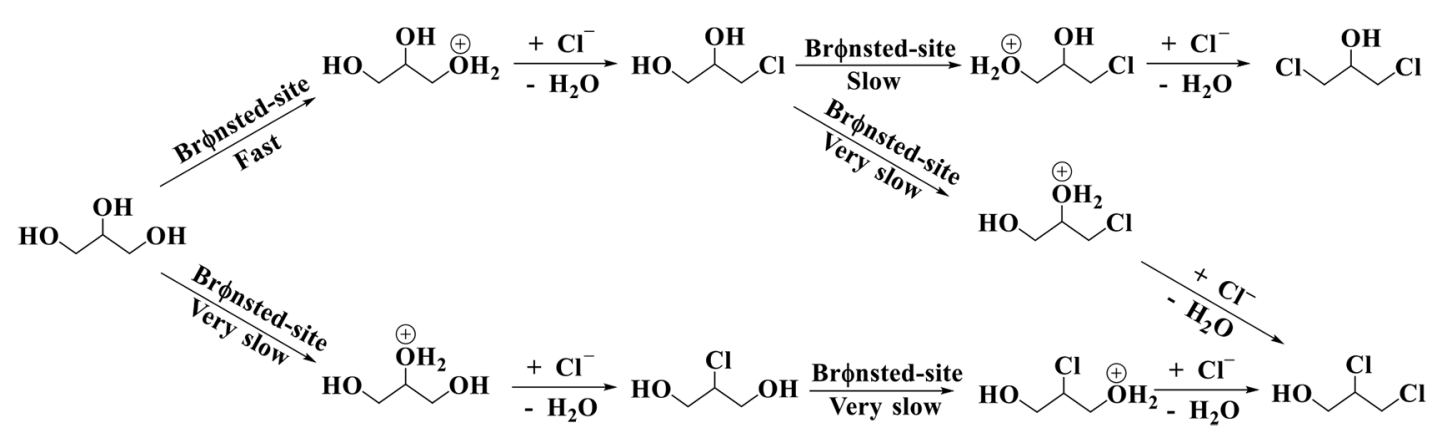

Scheme 1. The reaction routes in the chlorination of glycerol with gaseous $\mathrm{HCl}$ over Brønsted acidic ionic liquid catalysts. 
$[\mathrm{Bmim}] \mathrm{HSO}_{4} \mathrm{Br}$ nnsted acidic ionic liquid with the catalyst loading of $0.75 \mathrm{~mol} / \mathrm{kg}$ glycerol, the maximum yield of 3-MCPD of $85.39 \%$ was obtained at $130{ }^{\circ} \mathrm{C}$ for $6 \mathrm{~h}$.

\section{ACKNOWLEDGEMENTS}

This work was financially supported by the National Natural Science Foundation of China (21506082 and 21506078), Research Foundation of Jiangsu University (15JDG026), China Postdoctoral Science Foundation (2016M591786) and Jiangsu Planned Projects for Postdoctoral Research Funds (1601084B).

\section{REFERENCES}

Attri, P., Venkatesu, P., Hofman. T., Temperature dependence measurements and structural characterization of trimethyl ammonium ionic liquids with a highly polar solvent. The Journal of Physics Chemistry B, 115(33) 10086-10097 (2011). de Araujo Filho, C. A., Mondal, D., Haase S., Wärnå J., Eränen K., Mikkola, J. P., Salmi, T., Dynamic modelling of homogeneously catalyzed glycerol hydrochlorination in bubble column reactor. Chemical Engineering Science 149 277-295 (2016).

de Araujo Filho, C. A., Heredia, S., Eränen, K., Salmi, T., Advanced millireactor technology for the kinetic investigation of very rapid reactions: Dehydrochlorination of 1,3-dichloro-2-propanol to epichlorohydrin. Chemical Engineering Science 149 35-41 (2016).

Bui, T. L. T., Korth W., Jess, A., Influence of acidity of modified chloroaluminate based ionic liquid catalysts on alkylation of iso-butene with butene-2. Catalysis Communications, 25 118-124 (2012).

Carrà, S., Santacesaria, E., Morbidelli, M., Schwarz, P., Divo, C., Synthesis of epichlorohydrin by elimination of hydrogen chloride from chlorohydrins. 1. Kinetic aspects of the process. Industrial and Engineering Chemistry Process Design and Development, 18 424-427 (1979).

Chen, W. G., Yin, H. B., Zhang, Y. S., Lu, Z. Z., Wang, A. L., Shen, Y. T., Jiang, T. S., Yu, L. B., Acylation of salicylamide to 5-acetylsalicylamide using ionic liquids as dual catalyst and solvent. Journal of Industrial Engineering and Chemistry, 16, 800-804 (2010).

Choi, J. S. Simanjuntaka, F. S. H., Oh, J. Y., Lee, K. I., Lee, S. D., Cheong, M., Kim, H. S., Lee, H., Ionic-liquid-catalyzed decarboxylation of glycerol carbonate to glycidol. Journal of Catalysis, 297, 248-255 (2013).

Dasari, M. A., Kiatsimkul, P., Sutterlin, W. R., Suppes, G. J., Low-pressure hydrogenolysis of glycerol to propylene glycol. Applied Catalysis A: General, 281(1-2), 225-231 (2005).

Du, Y. Y., Tian, F. L., Zhao, W. Z., [BPy]HSO acidic ionic liquid as a novel, efficient, and environmentally benign catalyst for synthesis of 1,5-Benzodiazepines under mild conditions. Synthetic Communications, 36(12), 1661-1669 (2006).

Duan, Z. Y., Gu, Y. L., Zhang, J., Zhu, L. Y., Deng, Y. Q., Protic pyridinium ionic liquids: Synthesis, acidity determination and their performances for acid catalysis. Journal of Molecular Catalysis A: Chemical, 250(1-2), 163-168 (2006).

Fraga-Dubreuil, J., Bourahla, K., Rahmouni, M, Bazureau, J. P., Hamelin, J., Catalysed esterifications in room temperature ionic liquids with acidic counteranion as recyclable reaction media. Catalysis Communications, 3(5) 185-190 (2002).

Gade, S. M., Munshi, M. K., Chherawalla, B. M., Rane, V. H., Kelkar, A. A., Synthesis of glycidol from glycerol and dimethyl carbonate using ionic liquid as a catalyst. Catalysis Communications, 27 184-188 (2012).

Gómez-Jiménez-Aberasturi, O., Ochoa-Gómez, J. R., Pesquera-Rodríguez, A., Ramírez-López, C., Alonso-Vicario, A., Torrecilla-Soria, J., Solventfree synthesis of glycerol carbonate and glycidol from 3-chloro-1,2-propanediol and potassium (hydrogen) carbonate. Journal of Chemical Technology and Biotechnology, 85(12) 1663-1670 (2010).

Gu, Y. L., Zhang, J., Duan, Z. Y., Deng, Y. Q., Pechmann reaction in non-chloroaluminate acidic ionic liquids under solvent-free conditions. Advance Synthesis \& Catalysis. 347(4) 512-516 (2005).

Hou, X. X., Fu, Y. J., Zhu, X. Y., Yin, H. B., Wang, A. L., Chlorination of glycerol with $\mathrm{HCl}$ to 1,3-dichloro-2-propanol catalyzed by aliphatic carboxylic acids. Asia-Pacific Journal of Chemical Engineering, 10(4), 626-632 (2015).

Katryniok, B., Paul, S., Dumeignil, F., Recent developments in the field of catalytic dehydration of glycerol to acrolein. ACS Catalysis, 3(8) 18191834 (2013).

Li, X. Q., Yang, Y. X., Wang, W. L., Hu, B., Xue, H. M., Zhang, T. Y., Zhang, X. T., Asymmetric synthesis 
of L-carnitine from (R)-3-chloro-1,2-propanediol. Chinese Chemical Letters, 22(7), 765-767 (2011).

Ma, L., He, D., Li, Z., Promoting effect of rhenium on catalytic performance of $\mathrm{Ru}$ catalysts in hydrogenolysis of glycerol to propanediol. Catalysis Communications, 9(15) 2489-2495 (2008).

Nadato, N., Mori, H., Maki, K., Ishioka, R.; Process for production of epichlorohydrin. US. 4634784 (1987).

Ochoa-Gómez, J. R., Gómez-Jiménez-Aberasturi, O., Ramírez-López, C. A., Nieto-Mestre, J., MaestroMadurga, B., Belsué, M., Synthesis of glycerol carbonate from 3-chloro-1,2-propanediol and carbon dioxide using triethylamine as both solvent and $\mathrm{CO}_{2}$ fixation-activation agent. Chemical Engineering Journal, 175 505-511 (2011).

Olivier-Bourbigou, H., Magna, L., Ionic liquids: perspectives for organic and catalytic reactions. Journal of Molecular Catalysis A: Chemical, 182183, 419-437 (2002).

Pagliaro, M., Rossi, M., The Future of Glycerol, RSC Publishing, Cambridge (2010).

Qureshi, Z.S., Deshmukh. K. M., Bhor, M. D., Bhanage, B. M., Brönsted acidic ionic liquid as an efficient and reusable catalyst for transesterification of $: \hat{A}$-ketoesters. Catalysis Communication, 10(6), 83-8373 (2009).

Ramenskaya, L. M., Grishina, E. P., Pimenova, A. M., Gruzdev, M. S., The influence of water on the physicochemical characteristics of 1-butyl-3methylimidazolium bromide ionic liquid. Russian Journal of Physical Chemistry A, 82(7), 1098-1103 (2008).

Santacesaria, E., Tesser, R., Di Serio, M., Casale, L.,Verde, D., New process for producing epichlorohydrin via glycerol chlorination. Industrial \& Engineering Chemistry Research, 49(3), 964-970 (2010).

Shen, L. Q., Yin, H. B., Wang, A. L., Lu, X. F., Zhang, C. H., Gas phase oxidehydration of glycerol to acrylic acid over $\mathrm{Mo} / \mathrm{V}$ and $\mathrm{W} /$ Voxide catalysts. Chemical Engineering Journal, 244 168-177 (2014).

Shen, L. Q., Yin, H. B., Wang, A. L., Feng, Y. H., Shen, Y. T., Wu, Z. A., Jiang, T. S., Liquid phase dehydration of glycerol to acrolein catalyzed by silicotungstic, phosphotungstic, and phosphomolybdic acids. Chemical Engineering Journal, 180 277-283 (2012).

Song, S. H, Park, D. R., Woo, S. Y., Song, W. S., Kwon, M. S., Song, I. K., Direct preparation of dichloropropanol from glycerol and hydrochloric acid gas using heteropolyacid (HPA) catalyst by heterogeneous gas phase reaction. Journal of Industrial and Engineering Chemistry, 16(5) 662665 (2010).

Srivastava, R., Assessment of the catalytic activities of novel brönsted acidic ionic liquid catalysts. Catalysis Letter, 139(1-2), 17-25 (2010).

Tesser, R., Santacesaria, E., Di Serio, M., Di Nuzzi, G., Fiandra, V., Kinetics of glycerol chlorination with hydrochloric acid: A new route to ${ }_{i}, \dot{A},{ }_{\mid} \tilde{A}-$ dichlorohydrin. Industrial \& Engineering Chemistry Research, 46(20) 6456-6465 (2007).

Thomazeau, C., Olivier-Bourbigou, H., Magna, L., Luts, S., Gilbert, B., Determination of an acidic Scale in room temperature ionic liquids. Journal of the American Chemical Society, 125(18) 52645265 (2003).

Wang, A. L., Jiang, Y. Q., Chen, W. G., Yin, H. B., Liu, Y. J., Shen, Y. T., Jiang, T .S., Wu, Z. A., [BMIM] $\mathrm{Cl}-\mathrm{nAlCl}_{3}$ ionic liquid-catalyzed redistribution reaction between methyltrichlorosilane and lowboiling residue to dimethyldichlorosilane. Journal of Industrial and Engineering Chemistry, 18(1) 237-242 (2012).

Wang, W. J., Shao, L. L., Cheng, W. Q., Yang, J. G., He, M. Y., Brønsted acidic ionic liquids as novel catalysts for Prins reaction. Catalysis Communications, 9(3) 337-341 (2008).

Wang, Y. Y., Jiang, D., Dai, L. Y., Novel Brønsted acidic ionic liquids based on benzimidazolium cation: Synthesis and catalyzed acetalization of aromatic aldehydes with diols. Catalysis Communications, 9(15) 2475-2480 (2008).

Xiong, Y., Yang, M., Synthesis of the carboxyl and pyridine functional ionic liquids. Applied Mechanics and Materials, 513 246-250 (2014).

Yang, Y. L., Kou, Y., Determination of the Lewis acidity of ionic liquids by means of an IR spectroscopic probe. Chemistry Communication, 2, 226-227 (2004).

Yang, Y. X., Wang, W. L., Wumaier, A., Sheng, R. L., Zhang, X. T., Zhang, T. Y., Practical and efficient utilisation of (R)-3-chloro-1,2-propanediol in synthesis of L-carnitine. Journal of Chemical Research, 35(6), 371 (2011).

Yi, Y., Shen, Y., Sun, J., Wang, B., Xu, F., Sun, R., Basic ionic liquids promoted the synthesis of glycerol 1,2-carbonate from glycerol. Chinese Journal of Catalysis, 35(5) 757-762 (2014). 
Yu, H., Wu, Y. T., Jiang, Y. Y., Zhou, Z., Zhang, Z. B., Low viscosity amino acid ionic liquids with asymmetric tetraalkylammonium cations for fast absorption of $\mathrm{CO}_{2}$. New Journal of Chemistry, 33(12) 2385-2390 (2009).
Zhou, C., Beltramini, J.N., Fan, Y., Lu, G.Q., Chemoselective catalytic conversion of glycerol as a biorenewable source to valuable commodity chemicals. Chemical Society Reviews, 37(3) 527549 (2008). 